\title{
Fetal gender distribution in post-term pregnancy and intrauterine death: Maternal and neonatal outcomes by fetal sex
}

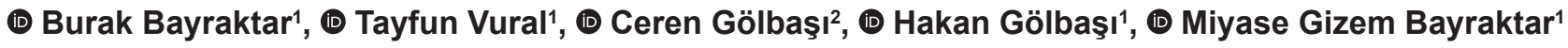 \\ 1 University of Health Sciences Turkey, Tepecik Training and Research Hospital, Clinic of Obstetrics and Gynecology, Izmir, \\ Turkey \\ 2Izmir Tinaztepe University Faculty of Medicine, Department of Obstetrics and Gynecology, Izmir, Turkey
}

Date submitted:

28.01.2021

Date accepted:

07.05.2021

Online publication date:

15.03.2022

\section{Corresponding Author:}

Burak Bayraktar, M.D., University of Health Sciences Turkey, Tepecik Training and Research Hospital, Clinic of Obstetrics and Gynecology, Izmir, Turkey

drburakbayraktar@gmail.com

ORCID:

orcid.org/0000-0001-6233-4207

Keywords: Post-term pregnancy, prolonged pregnancy, fetal sex, birth time, stillbirth, pregnancy outcome

\begin{abstract}
Aims: Fetal sex plays an important role in pregnancy and its outcomes due to hormonal and chromosomal differences. The current study examines the effect of fetal sex on delivery time, intrauterine death and maternal-neonatal outcomes.
\end{abstract}

Methods: Pregnant women who gave birth in University of Health Sciences Turkey, Tepecik Training and Research Hospital Delivery Unit between 2014 and 2019 were screened retrospectively for the study. Pregnancies of $\geq 37$ weeks ( 259 days) were included in the study, and pregnancies with $\geq 42$ weeks ( 294 days) were classified as post-term (prolonged) pregnancy. Intrauterine death and maternal-neonatal outcomes were compared according to fetal gender.

Results: The prevalence of post-term pregnancy was $0.76 \%$. A total of 45,147 pregnancies were found, including 22,788 (50.5\%) males (M) and 22,359 (49.5\%) females (F) who met our criteria for the study. In births between 37-40 0/6 weeks male sexes ratio was higher (M/F sex ratio: 37 0/6 weeks: $1.05 ; 380 / 6$ weeks: $1.01 ; 390 / 6$ weeks: 1.01$)$. The female sex birth rate becames more prominent after the $40^{\text {th }}$ week, $75 \%$ of the newborns at the $44^{\text {th }}$ week were observed to be female (M/F sex ratio: 44 0/6 weeks: 0.33 ). However, although female sex ratio was higher in post-term pregnancies, contrary to the literature, this difference was not significant. Intrauterine fetal death was observed more frequent in post-term pregnancies than term pregnancies $(0.93 \%$ vs $0.3 \%, p=0.017)$. The risk of intrauterine fetal death was approximately three times higher in post-term pregnancies than term pregnancies (Odds ratio: 3.16; 95\% confidence interval: 1.16-8.58). In post-term pregnancies, birth weight $(3458.7 \pm 462.9 \mathrm{~g}$ vs. $3338.5 \pm 416.5 \mathrm{~g})$, head circumference $(35.2 \pm 1.1 \mathrm{~cm}$ vs. $34.9 \pm 1 \mathrm{~cm})$ and body length $[50(44-56) \mathrm{cm}$ vs. $50(40-55) \mathrm{cm}]$ were higher in male sexes and all these results were statistically significant $(p=0.049, p=0.004$ and $\mathrm{p}=0.003$, respectively).

Conclusions: Contrary to the literature, fetal sex is not a significant risk factor in post-term pregnancy. But intrauterine death increases about 3-fold in post-term fetuses compared to term fetuses.

\section{Introduction}

Pregnancies $\geq 42$ weeks (294 days) from the last menstrual period are classified as post-term (prolonged) pregnancy $(1,2)$. Its incidence ranges between $0.4 \%$ and $10 \%$ (average, $7 \%$ ) (3-5). Although the etiology of post-term pregnancy is not fully known; genetic transition (6), anencephaly and placental sulfatase deficiency showing recessive passage linked to the $X$ chromosome (7), nulliparity (8), post-term pregnancy history (9), and maternal obesity (10) are thought to be the effective factors in prolonging pregnancy. Another factor discussed in post-term pregnancy etiology is fetal sex $(11,12)$.

Fetal sex is determined during fertilization, and accordingly, undifferentiated gonads differentiate into the ovarium or testicle. Although males carry one $X$ and one $Y$ chromosome, females contain two $X$ chromosomes. Thus, only males can encode the genes on the $Y$ chromosome. In females, genes from the two $X$ chromosomes can be encoded until one $X$ chromosome is inactivated. Inactivation is completed during the gastrulation 
phase (13). This difference between male and female sex is thought to be associated with the spontaneous abortion of the male sex (14), stillbirth $(15,16)$, neonatal morbidity, and mortality $(17,18)$, high operative birth, and cesarean rates $(18,19)$, preeclampsia $(16,20)$, and gestational diabetes $(16,21)$. Currently, preterm labor and premature rupture of membranes are considered common in male fetuses $(17,22,23)$. However, fetal sex as an etiologic factor in post-term fetuses is still controversial $(11,12,15)$.

Timing labor is important to achieve a good perinatal outcome. The objective of this study was to examine the association between fetal sex on delivery time and intrauterine fetal death. Additionally, we investigated the association of fetal sex and anthropometric measurements, APGAR score, and the need for neonatal intensive care unit (NICU) in post-term pregnancies.

\section{Methods}

\section{Study design and participants}

This single-center, retrospective study included pregnant women who delivered in the University of Health Sciences Turkey, Tepecik Training and Research Hospital Delivery Unit, Izmir, Turkey, between 2014 and 2019. Data were collected using electronic medical records and patient charts. The setting performs an average of 10,000 deliveries/year.

The last menstrual period (LMP) and crown-rump length $(C R L)$ in the first 6-14 weeks were used to determine the gestational age of the pregnancy. Dating was performed according to both dates for each pregnancy, and if the difference was more than 14 days, the dating value calculated according to $\mathrm{CRL}$ was accepted as gestational age. However, for pregnant women with unknown LMP, the dating value calculated according to $\mathrm{CRL}$ was accepted as gestational age. Pregnancies between 37-38 0/6, 39-40 0/6, 41-41 0/6, and $\geq 42$ weeks were defined and grouped as the early term, term, late-term, and post-term, respectively (2).

Multiple pregnancies, births before 37 weeks (259 days), pregnancies with chromosomal and/or major congenital anomalies, unavailable CRL measurement between the first 6-14 weeks, and those whose with missing information were excluded.

Pregnancies $\leq 19$ years and $\geq 35$ years were defined as adolescent pregnancies and advanced age pregnancies, respectively. Newborns weighing $<2500$ and $\geq 4000$ grams (g) were considered to have low birth weight (LBW) and macrosomia, respectively. The Helsinki Declaration was followed and ethics committee approval was obtained from the Ethics Committee of Health Sciences University Turkey, Tepecik Training and Research Hospital, Izmir, Turkey (approval no: 2020/14-8, date: 23.12.2020).

\section{Statistical Analysis}

The Statistical Package for the Social Sciences 22.0 version (IBM Corporation, Armonk, New York, US) was used for data analyses. The normality of distribution of variables was evaluated by the Kolmogorov-Smirnov test and Q-Q plot. Student's t-test was used to compare normally distributed variables and the data were given as mean \pm standard deviation. Mann-Whitney $U$ test was used to compare nonnormally distributed variables and the data were given as the median with minimum and maximum. Chi-square test was used to compare categorical variables and Odds ratio (OR) [95\% confidence interval $(\mathrm{CI})]$ calculations were made. $p<0.05$ was considered significant.

\section{Results}

A total of 45,147 pregnancies were identified, including $22,788(50.5 \%)$ male fetuses and 22,359 (49.5\%) female fetuses who met our criteria for the study. The prevalence of post-term pregnancy was $0.76 \%$. Fetal sex ratios according to gestational age are shown in Table 1. Accordingly, in births between 37-39 0/6 weeks, the male sex ratio was higher. The female sex birth ratio became more prominent after the $40^{\text {th }}$ week, and $75 \%$ of the newborns at the $44^{\text {th }}$ week were female; however, although the female sex ratio was higher in post-term pregnancies, the difference was not significant (Table 1).

Term pregnancies were classified according to gestational week. The male sex ratio was higher in early-term (37-38 0/6

\begin{tabular}{|llll|}
\hline Table 1. Fetal sex ratios by gestational age & & & \\
\hline Gestational age at birth, week & Male & Female & Male/female ratio \\
\hline $370 / 6, \mathrm{n}(\%)$ & $3226(52)$ & $2981(48)$ & 1.05 \\
\hline $380 / 6, \mathrm{n}(\%)$ & $6779(50.8)$ & $6561(49.2)$ & 1.01 \\
\hline $390 / 6, \mathrm{n}(\%)$ & $5991(50.9)$ & $5789(49.1)$ & 1.01 \\
\hline $400 / 6, \mathrm{n}(\%)$ & $5335(49.7)$ & $5392(50.3)$ & 0.96 \\
\hline $410 / 6, \mathrm{n}(\%)$ & $1261(47.3)$ & $1406(52.7)$ & 0.87 \\
\hline $420 / 6, \mathrm{n}(\%)$ & $183(46.1)$ & $214(53.9)$ & 0.82 \\
\hline $430 / 6, \mathrm{n}(\%)$ & $12(48)$ & $13(52)$ & 0.89 \\
\hline $440 / 6$ & $1(25)$ & $3(75)$ & 0.33 \\
\hline Total & $22788(50.5)$ & $22359(49.5)$ & 1.02 \\
\hline
\end{tabular}


weeks) and full-term (39-40 0/6 weeks) births, whereas the female sex ratio was higher in late-term (41-41 0/6 weeks) and post-term ( $\geq 42$ weeks) births (Table 2 ).

Table 3 shows the intrauterine fetal mortality rates by gestational week and fetal sex. Intrauterine fetal death ratio $(\mathrm{M} / \mathrm{F})$ in the early term, full-term, late-term, post-term was 1.1, $0.85,0.55$, and 0.58 , respectively, and the differences between male and female sex were not statistically significant. However, intrauterine fetal death was observed more frequently in postterm pregnancies than term pregnancies $(0.93 \%$ vs. $0.3 \%$, $p=0.017)$. The risk of intrauterine death was approximately three times higher in post-term pregnancies than the term pregnancies (OR: 3.16; 95\% Cl: 1.16-8.58) (Table 3).
The comparison of demographic characteristics of singleton post-term pregnancies classified based on fetal sex is shown in Table 4. Although the adolescent pregnancy rate was $9 \%$ and $11.7 \%$ in pregnant women with male and female fetuses, respectively, and the advanced age pregnancy rate was $14.2 \%$ and $12.1 \%$ in pregnant women with male and female fetuses, respectively, the differences between the groups were not statistically significant. No difference was found between the groups concerning parity, delivery types, cesarean types (primary-repeated), and first-trimester maternal body mass index (Table 4).

Table 5 shows the neonatal outcomes of live-singleton postterm pregnancies by classifying them according to the sex of the newborn. Birth weight $(3458.7 \pm 462.9 \mathrm{~g}$ vs. $3338.5 \pm 416.5$

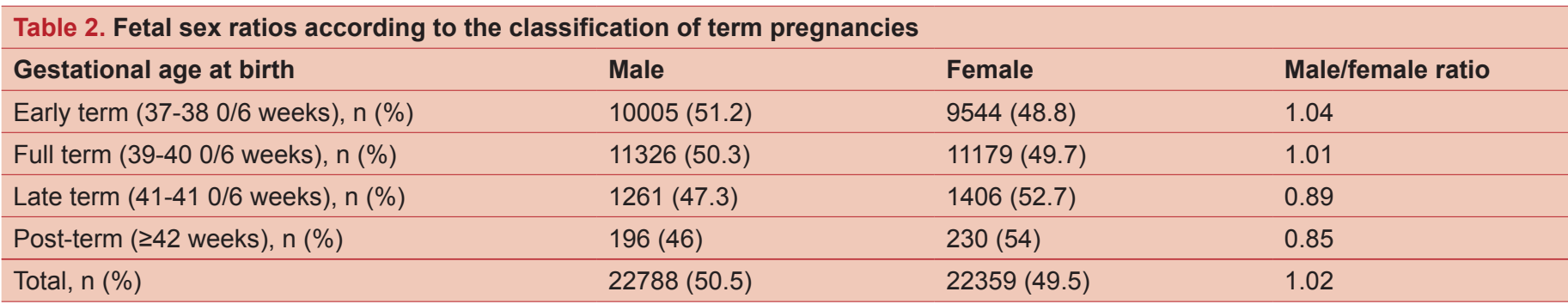

\begin{tabular}{|c|c|c|c|c|c|}
\hline Gestational age at birth & Male & Female & Male/female ratio & $95 \% \mathrm{Cl}$ & $\mathbf{p}$ \\
\hline Early term (37-38 0/6 weeks), n (\%) & $49(0.49)$ & $43(0.45)$ & 1.1 & $0.72-1.64$ & 0.689 \\
\hline Late term (41-41 0/6 weeks), n (\%) & $1(0.08)$ & $2(0.14)$ & 0.55 & $0.05-6.15$ & 0.628 \\
\hline Post-term ( $\geq 42$ weeks), n (\%) & $1(0.51)$ & $3(1.3)$ & 0.58 & $0.05-6.50$ & 0.397 \\
\hline
\end{tabular}

Table 4. Demogaphic properties of singleton post-term pregnancies ( $\geq 42$ weeks)

\begin{tabular}{|c|c|c|c|}
\hline & Male $(n=196)$ & Female $(n=230)$ & $\mathbf{p}$ \\
\hline Maternal age, years, median (min-max) & $26(15-41)$ & $26(14-43)$ & 0.702 \\
\hline Adolescent pregnancy $\leq 19, \mathrm{n}(\%)$ & $18(9)$ & $27(11.7)$ & 0.392 \\
\hline Parity, n (\%) & & & 0.656 \\
\hline Nulliparous & $92(46.9)$ & $103(44.7)$ & \\
\hline Gestational age, weeks, mean $\pm S D$ & $42.3 \pm 0.3$ & $42.3 \pm 0.4$ & 0.695 \\
\hline Delivery type $(n, \%)$ & & & 0.458 \\
\hline Vaginal delivery & $111(56.6)$ & $122(53)$ & \\
\hline Cesarean section & $85(43.4)$ & $108(47)$ & \\
\hline C-section type $(n, \%)$ & & & 0.829 \\
\hline
\end{tabular}


$\mathrm{g})$, head circumference $(35.2 \pm 1.1 \mathrm{~cm}$ vs. $34.9 \pm 1 \mathrm{~cm})$, and body length [50 (44-56) cm vs. $50(40-55) \mathrm{cm}]$ were higher in male neonates, and these results were all statistically significant $(p=0.049, p=0.004$, and $p=0.003$, respectively). The prevalence of LBW and macrosomia was similar for both sexes. No significant difference was found between the groups concerning the number of newborns with 1 st and 5th minute APGAR scores of $<7$ and the need for NICU (Table 5).

\section{Discussion}

In modern obstetrics, post-term pregnancy is considered a complex biological process closely related to factors, such as the chronological duration of pregnancy, onset mechanism of delivery, intrauterine fetal status and sex, and the fetoplacental system. Studies showed its prevalence as $0.4 \%, 0.6 \%, 2.3 \%$, and $8.1 \%$ in Austria, Belgium, Germany, and Denmark, respectively (3). The rate varies between $1 \%$ and $2.5 \%$ in America and Canada and $1.16 \%$ in China (24). To the best of our knowledge, our study is the largest study of post-term pregnancy populations in Turkey, and the post-term prevalence was $0.76 \%$ over 6 years. These differences may be due to differences in the management of labor induction between countries.

In our study, although the female sex ratio was higher in post-term pregnancies, contrary to the literature, this difference was not significant. In addition to studies showing that male sex is more common in post-term pregnancies $(11,25)$, some studies showed that female sex is more common $(12,15)$. The different results between studies may be due to three reasons. The main reason is the differences in the diagnosis of post-term pregnancy. Post-term pregnancy is most commonly diagnosed based on the incorrect calculations of the patient's LMP (26). Many women have menstrual cycle irregularities or follicular phase duration, and ovulation times may differ. Therefore, accurate determination of gestational age is important in post-term diagnosis and pregnancy management. Dating with ultrasonography measurements instead of only deciding based on LMP for gestational age reduces the post-term incidence from $10-15 \%$ to $2-5 \%$, and the best measurement method is the first-trimester CRL among other old ultrasonic measurements $(27,28)$. Therefore, gestational age was confirmed by dating according to 14 weeks CRL in addition to LMP, and if a difference of 14 days with LMP was observed, we accepted the ultrasound date as the gestational age. This study applies double validation (according to LMP and CRL combination) to minimize errors. Another reason that may lead to different results in different studies is the occurrence of racial differences (29). Finally, the sex ratio may change due to wars and natural disasters, and environmental factors $(24,30,31)$.

Post-term pregnancies cause a significant increase in perinatal morbidity and mortality $(32,33)$. When the gestational age exceeds 42 weeks, perinatal mortality increases 2-3 times compared with the 40 weeks gestation $(32,33)$. Our study showed similar results in which intrauterine death was observed approximately three times higher in post-term fetuses compared with term pregnant women (OR: 3.16 ; $95 \% \mathrm{Cl}$ : 1.16 8.58; $p=0.017$ ). The cause of intrauterine death was placental aging and uteroplacental insufficiency, meconium aspiration, and intrauterine infections (1). Especially, placental aging is speculated to be the cause of intrauterine death (34). Studies showed that placental mitochondria decreased, free oxygen radicals increased, and apoptosis increased in the placentas of post-term pregnant women (34). Additionally, amniotic fluid decreases as the pregnancy progresses. As gestation exceeds 40 weeks, the amount of AFI decreases by an average of $8 \%$ each week (35). Decreased AFI increases the risk of meconium aspiration.

When newborns of live-singleton post-term pregnancies were compared, birth weight, head circumference, and body length were higher in male newborns $(p=0.049, p=0.004$, and $p=0.003$, respectively). Similar to our study, previous studies showed that the weight, head circumference, and body length measurements of male newborns were higher than those of female newborns $(36,37)$. Theoretically, the anthropometric difference between male and female newborns is due to different growth rates in the intrauterine period. Many theories have been proposed to explain this sex-specific growth pattern. The most

\begin{tabular}{|llll|}
\hline \multicolumn{4}{|l|}{ Table 5. Neonatal outcomes among live-singleton post-term births $(\geq \mathbf{4 2}$ weeks) according to sex } \\
\hline & Male $(\mathbf{n = 1 9 5 )}$ & Female $(\mathbf{n = 2 2 7})$ & $\mathbf{p}$ \\
\hline Birth weight of newborns, $\mathrm{g}$, mean $\pm \mathrm{SD}$ & $3458.7 \pm 462.9$ & $3338.5 \pm 416.5$ & 0.049 \\
\hline Head circumference of newborns, cm, mean \pm SD & $35.2 \pm 1.1$ & $34.9 \pm 1$ & 0.004 \\
\hline Body length of newborns, $\mathrm{cm}$, median (min-max) & $50(44-56)$ & $50(40-55)$ & 0.003 \\
\hline LBW $(<2500 \mathrm{~g}), \mathrm{n}(\%)$ & $5(2.5)$ & $3(1.3)$ & 0.350 \\
\hline Macrosomia $(>4000 \mathrm{~g}), \mathrm{n}(\%)$ & $21(10.7)$ & $16(7)$ & 0.177 \\
\hline APGAR score $<7,1^{\text {st }}$ minute, $\mathrm{n},(\%)$ & $3(1.53)$ & $1(0.44)$ & 0.245 \\
\hline APGAR score $<7,5^{\text {th }}$ minute, $\mathrm{n}(\%)$ & $1(0.51)$ & $1(0.44)$ & 0.914 \\
\hline NICU hospitalization, $\mathrm{n}(\%)$ & $1(0.51)$ & $1(0.44)$ & 0.914 \\
\hline LBW: Low birth weight, NICU: Neonatal intensive care unit, min: Minimum, max: Maximum, SD: Standard deviation & \\
\hline
\end{tabular}


supported theory is that the male sex triggers fetal growth due to androgen secretion (38).

Macrosomia, intrapartum fetal distress, lower $1^{\text {st }}$ and $5^{\text {th }}$ minute APGAR scores are thought to be higher in postterm fetuses compared with term deliveries $(1,39,40)$. As far as we know, there is no study examining term pregnancies among themselves according to fetal sex. For the first time in the literature, perinatal results were compared based on fetal sex, but no statistically significant difference was observed between the male and female sexes. In contrast to the literature regarding term pregnancies $(15,18)$, the male sex does not pose any additional risk in post-term fetuses. The different results in previous studies may be due to the calculation of gestational age without dating.

This study has several limitations, including the retrospective design and single-center observations. The exclusion of pregnant women without CRL measurement in the first trimester (6-14 weeks) is a strength, preventing mistakes in the post-term decision.

\section{Conclusion}

In conclusion, this study showed that, contrary to the literature, fetal sex is not a significant risk factor in post-term pregnancy. However, post-term pregnancy has a higher risk of intrauterine death compared with term pregnancies.

\section{Ethics}

Ethics Committee Approval: The study was obtained from the Ethics Committee of Health Sciences University Turkey, Tepecik Training and Research Hospital (approval number: 2020/14-8, date: 23.12.2020).

Informed Consent: Retrospective study.

Peer-review: Externally peer-reviewed.

\section{Authorship Contributions}

Concept: B.B., T.V., Design: B.B., C.G., H.G., M.G.B., Data Collection or Processing: B.B., T.V., Analysis or Interpretation: B.B., T.V., C.G., H.G., M.G.B., Literature Search: B.B., T.V., C.G., H.G., M.G.B., Writing: B.B., T.V., C.G., H.G., M.G.B.

Conflict of Interest: No conflict of interest was declared by the authors.

Financial Disclosure: The authors declared that this study received no financial support.

\section{References}

1. ACOG Committee on Practice Bulletins. ACOG Practice Bulletin: clinical management guidelines for obstetriciangynecologists. Number 45, August 2003. Cervical cytology screening (replaces committee opinion 152, March 1995). Obstet Gynecol. 2003;102:417-427.
2. Spong CY. Defining "Term" Pregnancy: Recommendations From the Defining "Term" Pregnancy Workgroup. JAMA. 2013;309:2445-2446.

3. Zeitlin J, Blondel B, Alexander S, Bréart G; PERISTAT Group. Variation in rates of postterm birth in Europe: reality or artefact? BJOG: Int J Obstet. Gynaecol 2007;114:1097-1103.

4. Martin JA, Hamilton BE, Osterman MJK, Driscoll AK, Drake P. Births: Final Data for 2017. National Vital Statistics Reports. 2018;67:1-50.

5. Deng K, Huang Y, Wang Y, et al. Prevalence of postterm births and associated maternal risk factors in China: data from over 6 million births at health facilities between 2012 and 2016. Sci Rep. 2019;9:273.

6. Laursen M, Bille C, Olesen AW, Hjelmborg J, Skytthe A, Christensen K. Genetic influence on prolonged gestation: A population-based Danish twin study. Am J Obstet Gynecol. 2004;190:489-494.

7. Doherty L, Norwitz ER. Prolonged pregnancy: when should we intervene? Curr Opin Obstet Gynecol. 2008;20:519-527.

8. Galal M, Symonds I, Murray H, Petraglia F, Smith R. Postterm pregnancy. Facts Views Vis Obgyn. 2012;4:175-187.

9. Kistka ZA, Palomar L, Boslaugh SE, DeBaun MR, DeFranco EA, Muglia LJ. Risk for postterm delivery after previous postterm delivery. Am J Obstet Gynecol. 2007;196:241.

10. Roos N, Sahlin L, Ekman-Ordeberg G, Kieler H, Stephansson O. Maternal risk factors for postterm pregnancy and cesarean delivery following labor induction. Acta Obstet Gynecol Scand. 2010;89:1003-1010.

11. Divon MY, Ferber A, Nisell H, Westgren M. Male gender predisposes to prolongation of pregnancy. Am J Obstet Gynecol. 2002;187:1081-1083.

12. Kitlinski Laczna M, Källén K, Marsál K, Olofsson P. Skewed fetal gender distribution in prolonged pregnancy: a fallacy with consequences. Ultrasound Obstet Gynecol. 2003;21:262-266.

13. Goto T, Monk M. Regulation of X-Chromosome Inactivation in Development in Mice and Humans. Microbiol Mol Biol Rev. 1998;62:362-378.

14. Byrne J, Warburton D. Male excess among anatomically normal fetuses in spontaneous abortions. Am J Med Genet. 1987;26:605-611.

15. Vatten LJ, Skjaerven R. Offspring sex and pregnancy outcome by length of gestation. Early Hum Dev. 2004;76:47-54.

16. Mondal D, Galloway TS, Bailey TC, Mathews F. Elevated risk of stillbirth in males: systematic review and meta-analysis of more than 30 million births. BMC Med. 2014;12:220.

17. Peelen MJ, Kazemier BM, Ravelli AC, et al. Impact of fetal gender on the risk of preterm birth, a national cohort study. Acta Obstet Gynecol Scand. 2016;95:1034-1041.

18. Bekedam DJ, Engelsbel S, Mol BW, Buitendijk SE, van der Pal-de Bruin KM. Male predominance in fetal distress during labor. Am J Obstet Gynecol. 2002;187.1605-1607.

19. Aibar L, Puertas A, Valverde M, Carrillo MP, Montoya F. Fetal sex and perinatal outcomes. J Perinat Med. 2012;40:271-276. 
20. Stark MJ, Dierkx L, Clifton VL, Wright IM. Alterations in the maternal peripheral microvascular response in pregnancies complicated by preeclampsia and the impact of fetal sex. J Soc Gynecol Investig. 2006;13:573-578.

21. Ehrlich SF, Eskenazi B, Hedderson MM, Ferrara A. Sex ratio variations among the offspring of women with diabetes in pregnancy. Diabet Med. 2012;29:273-278.

22. Lao TT, Sahota DS, Suen SS, Law LW. The impact of fetal gender on preterm birth in a southern Chinese population. J Matern Fetal Neonatal Med. 2011;24:1440-1443.

23. Challis J, Newnham J, Petraglia F, Yeganegi M, Bocking A. Fetal sex and preterm birth. Placenta. 2013;34:95-99.

24. Hesketh T, Xing ZW. Abnormal sex ratios in human populations: Causes and consequences. Proc Natl Acad Sci. 2006;103:13271-13275.

25. Björkman K, Wesström J. Risk for girls can be adversely affected post-term due to underestimation of gestational age by ultrasound in the second trimester. Acta Obstet Gynecol Scand. 2015;94:1373-1379.

26. Crowley $\mathrm{P}$, O'Herlihy $\mathrm{C}$, Boylan $\mathrm{P}$. The value of ultrasound measurement of amniotic fluid ume in the management of prolonged pregnancies. Br J Obstet Gynaecol. 1984;91:444448.

27. Caughey AB, Nicholson JM, Washington AE. First- vs secondtrimester ultrasound: the effect on pregnancy dating and perinatal outcomes. Am J Obstet Gynecol. 2008;198:703.

28. Bennett KA, Crane JM, O'shea P, Lacelle J, Hutchens D, Copel JA. First trimester ultrasound screening is effective in reducing postterm labor induction rates: A randomized controlled trial. Am J Obstet Gynecol. 2004;190:1077-1081.

29. Chao F, Gerland P, CookAR, Alkema L. Systematic assessment of the sex ratio at birth for all countries and estimation of national imbalances and regional reference levels. Proc Natl Acad Sci. 2019;116:9303-9311.

30. Zorn B, Sucur V, Stare J, Meden-Vrtovec H. Decline in sex ratio at birth after 10-day war in Slovenia: brief communication. Hum Reprod. 2002;17:3173-3177.

31. Peterka M, Peterková R, Likovský Z. Chernobyl: Relationship between the Number of Missing Newborn Boys and the Level of Radiation in the Czech Regions. Environ Health Perspect. 2007;115:1801-1806.

32. Feldman GB. Prospective Risk of Stillbirth. Obstet Gynecol. 1992;79:547-553.

33. Hilder L, Costeloe K, Thilaganathan B. Prolonged pregnancy: evaluating gestation-specific risks of fetal and infant mortality. Br J Obstet Gynaecol. 1998;105:169-173.

34. Carroll A, Lee S, Desforges M, Heazell AEP. A review of the Evidence for Placental Ageing in Prolonged Pregnancy. Med Res Arch. 2020;8:2-20.

35. Brace RA, Wolf EJ. Normal amniotic fluid volume changes throughout pregnancy. Am J Obstet Gynecol. 1989;161:382388.

36. Guihard-Costa AM, Grangé G, Larroche JC, Papiernik E. Sexual Differences in Anthropometric Measurements in French Newborns. Biol Neonate. 1997;72:156-164.

37. Cogswell ME, Yip R. The influence of fetal and maternal factors on the distribution of birthweight. Semin Perinatol. 1995;19:222-240.

38. Thomson AM, Billewicz WZ, Hytten FE. The assessment of fetal growt. J Obstet Gynaecol Br Commonw. 1968;75:903916.

39. Rosen MG, Dickinson JC. Management of Post-Term Pregnancy. N Engl J Med. 1992;326:1628-1629.

40. Kitlinski ML, Källén K, Marsál K, Olofsson P. Gestational agedependent reference values for $\mathrm{pH}$ in umbilical cord arterial blood at term. Obstet Gynecol. 2003;102:338-345. 